quả hơn. Nhiêu BN đã thay đổi được hành vi lối sống làm tăng nguy cơ biến chứng nguy hiểm của bệnh THA như bỏ hút thuốc lá, ăn giảm mặn, hạn chế uống rượ/bia, tăng cường hoạt động thể lực đều đặn hàng ngày... và đã hài lòng hơn với chất lượng dịch vụ KCB, CSSK của TYT xã.

\section{KẾT LUẬN}

Quá trình áp dụng nguyên lý YHGĐ vào hoạt động của TYT hai xã Mai Đình và Phú Minh, các TYT đã được các BV tuyến trên/tuyến cuối đặc biệt là BV Tim Hà Nội đào tạo, tập huấn nâng cao trình độ chuyên môn, năng lực quản lý điều trị BN THA, kiến thức, kỹ năng tư vấn, GDSK, kỹ năng giao tiếp với $B N$ và trực tiếp tham gia hố trợ, hướng dẩn "cầm tay chỉ việc" cho cán bộ, nhân viên y tế kỹ năng thực hành KCB tại TYT; tỷ lệ BN THA đăng ký quản lý tại hai TYT xã tăng lển rõ rệt, từ $76,7 \%$ và $74,4 \%$ (2014) lên $89,8 \%$ và $90,5 \%(2020)(p<0,001) ; B N$ được quản lý điều trị THA tại TYT đã thay đổi hành vi lối sống theo hướng tích cực, khoa học, giảm được nguy cơ biến chứng nguy hiểm của THA như bỏ hút thuốc lá, ăn giảm mặn, hạn chế uống rượ/bia, tăng cường hoạt động thể lực hàng ngày và hài lòng hơn với chất lượng dịch vụ KCB của TYT.

\section{TÀI LIÊU THAM KHẢO}

1. Nguyễn Lân Việt, Đỗ Doãn Lợi, Phạm Thái Sớn và CS (2008). Áp dụng một số giải pháp can thiệp thích hợp để phòng, chữa bệnh tăng huyết áp ơ cộng đồng, Đề tài nghiên cứu khoa học cấp Bộ của Đại học Y Hà Nội.

2. NCD-RisC (2017). Worldwide trends in blood pressure from 1975 to 2015, The Lancet, 398: 37-55.

3. Nguyễn Thị Kim Chúc và Nguyễn Hoàng Long (2010). Mô hình tử vong ở Việt Nam, kết quả tữ nghiên cứu điều tra nguyên nhân tứ vong bằng phương pháp phỏng vấn. Tạp chí Nghiên cứu $Y$ hoc, 70 (5): 56-61.

4. Nguyễn Lân Việt (2011). Tăng huyết áp - Vấn đề cần đước quan tâm, Hội nghị Chương trình mục tiêu Quốc gia Phòng chống tăng huyết app, Hà Nội.

5. World Health Organization (2005). A global brief on Hypertension Silent Killer. Global Public Health Crisis, 1-40.

6. Ban chấp hànhTw Đảng CSVN (2017). Nghị quyết số 20-NQ/TW ngày 25/07/2017 của Ban chấp hành TW Đảng về tăng cường công tác bảo vệ, chăm sóc và nâng cao sức khoẻ nhân dân trong tình hình mới

7. Bộ Y tế (2012). Đề án xây dựng và phát triển mô hình phòng khám bác sĩ gia đỉnh tại Việt Nam giai đoan 2013-2020.

8. Huyện Ủy Sóc Sơn, Hà Nội (2016). Chỉ thị số 09CT/HUU về tăng cường sự lãnh đạo của Đảng về triển khai thực hiện mô hinh phòng khám Bác sỹ gia đinh trên địa bàn huyện, ban hành ngày 17/7/2016.

\title{
NĂNG LỰC SỨC KHOẺ VỀ PHÒNG CHỐNG BÊNH SỐT RÉT CỦA NGƯỜI DÂN XÃ IAPIO'R, HUYÊ̂N CHƯ PRÔNG, TỈNH GIA LAI
}

\section{TÓM TẮT}

Đặt vấn đề: Sốt rét hiện nay vẫn còn là một vẫn đề sức khỏe quan trọng trên thế giới nói chung và Việt Nam nói riêng. Hiện nay chưa có vắc xin phòng bệnh do đó việc lưa chọn giải pháp dự phòng đối với bệnh sốt rét là rẩt quan trong. Chư Prông Là một huyện thuộc tỉnh Gia Lai, huyện tập trung nhiêu dân tộc thiểu số, trình đô học vấn thẩp, kinh tế khó khăn, khó tiếp cận với nguồn thông tin vê phòng chống sốt rét. Do đó cần có một nghiên cứu đánh giá năng lực sức khoẻ về phòng chống sốt rét, để từ đó đưa ra một giải pháp can thiệp phù hợp hiệu quả hơn. Mục tiêu: xác định tỳ lệ người dân tại xã̃ Iapiơ, huyện Chư Prông, tỉnh Gia L̇ai năm 2021 có kiến thức, thực hành đúng về phòng chống sốt rét và các yếu tố liên quan về kiến thức, thái độ, thực hành. Kết quả: Tỷ lệ kiến thức chung, thực hành chung đúng lần lượt là 37\%,

*Đai hoc Y Dược Thành phố Hồ Chí Minh

Chịu trách nhiệm chính: Đoàn Duy Tân

Email: doanduytaan@ump.edu.vn

Ngày nhận bài: 8.9.2021

Ngày phản biện khoa học: 15.10.2021

Ngày duyệt bài: 10.11.2021
Phong*, Nông Văn Minh*, Đoàn Duy Tân*

$14,6 \%$. Có mối liên quan giữa kiến thức chung với thực hành chung. Có mối liên quan giữa kiến thức chung với nghề nghiệp, trình độ học vẩn, tiền sử bản thân có mắc sốt rét, tiên sử gia đỉnh có mắc sốt rét. Kết luận: Tỷ lệ người dân có năng lực chăm sức khoẻ về phòng chống sốt rét còn rất thấp. Các yếu tố liên quan đến kiến thức chủ yếu là trình độ học vấn và tiển sử bản thân và gia đình mắc sốt rét. Mối liên quan giữa tỷ lệ kiến thức chung với thực hành chung là có ý nghĩa thống kê.

Tư khóa: năng lực sức khoẻ, phòng chống sốt rét.

\section{SUMMARY}

HEALTH LITERACY PREVENT MALARIA IN IAPIO'R COMMUNE, CHU PRONG TOWN, GIA LAI PROVINCE

Background: Malaria today is still an important health condition in the global scale in general and in Vietnam in particular. At the present, there has not been any kind of vaccination, so choosing a preventive method is imperative. Chu Prong is a town in Gia Lai province, and this place is populated by ethnic groups with very low levels of education, difficult economic situation and the hardship in accessing sources of information about preventing malaria. Thus, there 
should be a study to assess the capacity to prevent malaria, thereby coming up with a measure to deal with the problem properly. Objectives: To determine the proportion of people residing in Iapio commune, Chư Prông town, Gia Lai province in 2021 who have enough knowledge towards malaria, and practice the preventive methods properly; alongside other related factors about knowledge and practice. Results: The percentage of precise general knowledge and practice knowledge accounted for $37 \%, 14.6 \%$ respectively. There was a connection between general knowledge and practice knowledge. There was a connection between general knowledge with occupations, levels of education, medical history of getting malaria, and family members' medical history of getting malaria. Conclusions: The percentage of people who have the capacity to prevent malaria was still low. Other factors related to the knowledge were mostly their levels of education and personal as well as family's medical history of getting malaria. The connection between the percentage of general knowledge with practice knowledge was statistically significant.

Keywords; health literacy, malaria prevention

\section{I. ĐẶT VẤN ĐỀ}

Sốt rét là một bệnh truyền nhiễm có thể bùng phát dịch và gầy tử vong nếu không được điều trị kịp thời. Tại Việt Nam, bệnh SR là một vấn đề sức khỏe cộng đồng cần được quan tẩm, bệnh phổ biến với gần 40 triệu người sống trong vùng nguy cơ SR, khoảng 15 triệu người sống trong vùng sốt rét lưu hành. Bệnh lan truyền và gây ti lệ mắc cao chủ yếu ở vùng rừng núi, vùng sâu vùng xa, nơi có nhiều cộng đồng dân tộc ít người sinh sống và dân di cư từ vùng không có sốt rét lưu hành tới vùng sốt rét lưu hành, đặc biệt tại khu vực miền Trung - Tây Nguyên [1], [2], [3]. Miền Trung -Tây Nguyên vẫn là khu vực có nguy cơ SR cao nhất so với các khu vực khác trong nước. Hàng năm bệnh nhân SR (BNSR) chiếm $50 \%$, ký sinh trùng sốt rét (KSTSR) chiếm $75 \%$, sốt rét ác tính (SRAT) và tử vong sốt rét (TVSR) chiếm trên $80 \%$ so với cả nước [4]. Theo thống kê của Viên Sốt rét - Ký sinh trung - Côn trùng Quy Nhơn năm 2019, Gia Lai có số BNSR tăng cao so với cùng kỳ năm 2018 chiếm 59,67\% (từ 1106 lên $1766 \mathrm{ca}$ ) [5]. Chính vì vây, nghiên cứu được thực hiện với mong muốn có những đóng góp nhất định cho y văn, đóng góp cho y tế và chiến dịch phòng chống SR tại địa phương, đặc biệt là truyền thông giáo dục sức khỏe cho người dân.

\section{II. ĐỐI TƯỢNG VÀ PHƯƠNG PHÁP NGHIÊN CỨU}

Đối tượng nghiên cứu: người dân từ 18-60 tuổi thường trú tại xã Iapiơr, huyện Chư Prông tỉnh Gia Lai đồng ý tham gia nghiên cứu trong khoảng thời gian từ tháng $4-5 / 2021$. Loại những người dân trả lời được ít hơn 70\% bộ câu hỏi và những người dân vắng mặt trong tất cả các buổi thu thập dữ liệu.

Thiết kế nghiên cứu: Nghiên cứu mô tả cắt ngang.

Cỡ mẫu: Mẫu được chọn bằng phương pháp chon mẫu phân tầng, sử dụng công thức tính cỡ mấu ước lượng một tî lệ:

$$
n=\frac{z_{\left(1-\frac{\alpha}{2}\right) \times P \times(1-P)}^{2}}{d^{2}}
$$

Trong đó: n: cõ̃ mẫu tối thiểu cần nghiên cứu, Z: trị số trong bảng phân phối chuẩn, $Z=1,96$ khi $\mathrm{a}=0,05, \mathrm{p}$ : Kiến thức phòng chống sốt rét $=0,2$ [6], d: sai số tương đối, chọn $\mathrm{d}=0,05$. Vậy cỡ mầu cần cho nghiên cứu là 246 người dân.

Biến số nghiên cứu: Kiến thức chung phòng chống sốt rét: là biến số nhị giá với hai giá trị

Có: có kiến thức chung phòng chống sốt rét đúng khi biết về triệu chứng sốt rét, trung gian truyền bệnh là muỗi, nơi đẻ trứng của muổi, biết về biện pháp phòng chống sốt rét.

Không: kiến thức phòng chống sốt rét chưa đúng khi không biết đủ các ý nêu trên.

Thực hành chung phòng chống sốt rét: là biến nhị giá có 2 giá trị

Đúng: có thực hành đúng về phòng chống sốt rét qua phỏng vấn khi có là luôn luôn ngủ mùng (kể cả khi ngử ở rừng), có tẩm mùng bằng hóa chất diệt muỗi, thực hành đúng về bảo quản mùng tẩm hóa chất. Có thực hành đúng qua quan sát là có ít nhất một dụng cụ bình xịt muỗi, nhang muỗi, kem chống muô̂i, quạt, vợt điện, mùng, đậy kín nắp dụng cụ chứa nước sinh hoạt.

Chưa đúng: khi thực hiện thiếu và không đầy đủ các biện pháp uôn luôn ngủ mùng (kể cả khi ngủ ở rừng), có tẩm mùng bằng hóa chất diệt muỗi, thực hành đúng về bảo quản mùng tẩm hóa chất. Có thực hành đúng qua quan sát là có ít nhất một dụng cụ bình xịt muỗi, nhang muỗi, kem chống muỗi, quạt, vợt điện, mùng, đậy kín nắp dụng cụ chứa nước sinh hoạt.

Xử lý và phân tích số liệu: Sử dụng phần mềm Epidata 3.1 để nhập liệ́u. Xử lý và phân tích dữ kiện bằng phần mềm Excel của Office 365 và phần mềm Stata 14.3.

\section{KẾT QUẢ NGHIÊN CỨU VÀ BÀN LUÂ̂N \\ Bảng 1. Đặc điểm mấu nghiên cứu $(n=246)$}

Đặc tính mâu nghiên cứu Tần số(n)Tỉ lệ(\%)

\begin{tabular}{|c|c|c|}
\hline Nhóm tuối: $18-39$ & 108 & 43,9 \\
$\geq 40$ & 138 & 56,1 \\
\hline Giới tính: Nữ & 112 & 45,5 \\
Nam & 134 & 54,5 \\
\hline Dân tộc: Kinh & 102 & 41,5 \\
\hline
\end{tabular}




\begin{tabular}{|c|c|c|}
\hline Giarai & 16 & 6,5 \\
Tày & 31 & 12,6 \\
Mông & 17 & 6,9 \\
Khác & 79 & 58,5 \\
\hline Nghề nghiệp & & \\
Nông dân & 211 & 85,7 \\
Công nhân viên chức & 26 & 10,6 \\
Khác & 9 & 3,7 \\
\hline Trình độ học vấn & & \\
Biết đọc biết viết & 68 & 27,6 \\
Tiểu học & 34 & 13,8 \\
Trung học cơ sở & 92 & 37,4 \\
Trung học phổ thông & 21 & 8,6 \\
Trung cấp, Cao đẳng, Đại học & 29 & 11,8 \\
Sau đại học & 2 & 0,8 \\
\hline Kinh tế gia đình & & \\
Hộ nghèo & 45 & 18,3 \\
Không thuộc hộ nghèo & 201 & 81,7 \\
\hline Tiền sử mắc sốt rét & & \\
Bản thân (có) \\
Gia đình (có)
\end{tabular}

Trong 246 mấu khảo sát, tuối trung bình là 40 tuổi, nhóm tuổi nhóm tuổi từ 40 tuổi trở lên chiếm $56,1 \%$. Về giới tính, tỉ lệ nam giới chiếm tỉ lệ $54,5 \%$. Nghề nghiệp chủ yếu là nông dân chiếm $85,7 \%$. Về học vấn, tỉ lệ học vấn trung học cơ sở chiếm cao nhất $37,4 \%$, xếp thứ hai là biết đọc biết viết chiếm 27,6. Tình trạng kinh tế hộ nghèo chiếm khá cao là 18,3\%. Tiền sử bản thân mắc sốt rét là $11,4 \%$ và tiền sử gia đình mắc sốt rét là $22,4 \%$ gần gấp đôi tiền sử bản thân mắc sốt rét

Bảng 2. Các nguôn thông tín về phòng chống sốt rét ( $n=246)$

\begin{tabular}{|c|c|c|}
\hline $\begin{array}{c}\text { Đắc tính mâuu } \\
\text { nghiên cứu }\end{array}$ & Tân số $\mathbf{( n )}$ & Tỉ lệ (\%) \\
\hline $\begin{array}{c}\text { Nghe về sốt rét } \\
\text { Đã tứng nghe }\end{array}$ & 226 & 92,2 \\
Chưa tứng nghe & 19 & 7,8 \\
\hline Nguồn thông tin & & \\
Tivi & 203 & 89,4 \\
Radio & 44 & 19,4 \\
Loa truyền thanh & 63 & 27,7 \\
Sách báo-tranh & 63 & 27,7 \\
ảnh-tờ rời & 79 & 34,8 \\
Bạn bè người thân & 136 & 59,9 \\
Cán bộy yế & 4 & 1,2 \\
Nguồn khác & & \\
\hline
\end{tabular}

Đa số người dân đã từng nghe về bệnh sốt rét chiếm 92,2\%. Người dân biết đến bệnh sốt rét qua các nguồn thông tin chiếm chủ yếu là tivi $(89,4 \%)$, cán bộ y tế $(59,9 \%)$, bạn bè người thân $(34,8 \%)$, loa truyền thanh và sách báo tranh ảnh tờ rơi $(27,7 \%)$, thông tin từ radio $(19,4 \%)$ chiếm tỉ lệ khá thấp có thể do đa sô được thay bằng tivi và các phương tiên khác.

Bảng 3. Kiến thức về phòng chống bệnh sốt rét $(n=246)$

\begin{tabular}{|c|c|c|}
\hline Kiến thức & Tân số (n) & Tỉ lệ (\%) \\
\hline Kiến thức đúng về triệu chứng của bệnh sốt rét & 114 & 46,3 \\
\hline Kiến thức đúng về trung gian truyền bênh là muỗi & 196 & 79,7 \\
\hline Kiến thức đúng về nơi muỗi thường đẻ trứng & 244 & 99,2 \\
\hline Kiến thức đúng về biện pháp phòng chống sốt rét & 199 & 80,9 \\
\hline Kiến thức đúng về đối tượng có thể mắc bệnh sốt rét & 229 & 93,1 \\
\hline Kiến thức đúng về đường lây truyền của bểnh sốt rét & 113 & 57,4 \\
\hline Kiến thức đúng về thời gian hoạt động của muỗi truyền bệnh sốt rét & 168 & 85,3 \\
\hline Kiến thức đúng về bảo quản mùng sau khi tẩm hóa chất & 48 & 19,5 \\
\hline & 91 & 37 \\
\hline
\end{tabular}

Có $37 \%$ số người trong mẫu khảo sát hiếu biết đúng về triệu chứng bệnh sốt rét, tác nhân truyền bệnh là muỗi, vị trí muỗi đẻ trứng, cách phòng chống muỗi đốt, tỉ lệ này khá thấp. Nhìn chung, kết quả nghiên cứu về kiến thức chung đúng trong phòng chống sốt rét khá thấp chỉ chiếm $37,0 \%$, cao hơn nghiên cứu của tác giả Lê Hữu Hòa trên đồng bào S'tiêng và Mnông tại Bình Phước năm 2004 với tỉ lệ 22,9\% [5], [7], [8]. Kết quả này cao hơn có thể do địa điểm và đối tượng nghiên cứu các nhau. Nghiên cứu của Lê Hữu Hòa thực hiện trên đối tượng dân tộc S'tiêng và Mnông, còn nghiên cứu của này thực hiện trên tất cả các dân tộc có tại xã Iapiơr, trong đó dân tộc Kinh tham gia nghiên cứu chiếm tỉ lệ $41,5 \%$.

Bảng 4. Thực hành chung về phòng chống bệnh sôt rét $(n=246)$

\begin{tabular}{|c|c|c|}
\hline Thực hành & Tân số (n) & Tỉ lệ (\%) \\
\hline Luôn luôn ngủ mùng (kể cả khi ngủ ở rừng) & 224 & 91,4 \\
Tẩm mùng bằng hóa chất diệt muối & 127 & 51,8 \\
Bảo quản mùng đúng & 42 & 17,1 \\
Mang theo thuốc sốt rét khi đi làm & 20 & 36,4 \\
Thực hành đúng qua quan sát các dụng cụ diệt, phòng chống muỗi & 239 & 100,0 \\
\hline
\end{tabular}




\begin{tabular}{|c|c|c|}
\hline Thực hành đúng qua quan sát đậy kín nắp dụng cụ chứa nước sinh hoạt & 192 & 78,1 \\
\hline Thực hành đúng qua quan sát dụng cụ chứa nước sinh hoạt không có lăng quăng & 122 & 49,6 \\
\hline $\begin{array}{l}\text { Thực hành đúng qua quan sát không có vật phế thải có thể đọng nước xung } \\
\text { quanh nhà }\end{array}$ & 113 & 45,9 \\
\hline Thực hành đúng qua quan sát thả cá vào dụng cụ chứa nước sinh hoạt & 37 & 15,1 \\
\hline Thực hành chung đúng & 36 & 14,6 \\
\hline
\end{tabular}

Chỉ có $14,6 \%$ số người được quan sát có thực hành chung đúng (tẩm mùng, bảo quản mùng đúng khi tẩm hóa chất, luôn luôn ngủ mùng và có sử dụng dụng cụ diệt, phòng chống muỗi, đậy kín nắp dụng cụ chứa nước sinh hoạt). Kết quả này có sự chênh lệch so với kết quả nghiên cứu của Luân Thị Nhung thực hiện tại huyện Bù Đăng tỉnh Bình Phước năm 2018" với tỉ lệ 15,9\% [6]. Kết quả sự khác biệt này có thể liển quan đển phần kiến thức chung, trong nghiên cứu của Luân Thị Nhung kiến thức chung là $20,6 \%$ và những người có kiến thức đúng có tî lệ thực

hành đúng cao gấp 8,63 lần so với những người chưa có kiến thức đúng. Còn kết quả nghiên cứu này kiến thức chung đúng $37 \%$ cao hơn nghiên cứu Luân Thị Nhung [6], nhưng người có kiến thức đúng có tî lệ thực hành đúng so với người chưa có kiến thức đúng là 2,67 lần thấp hơn 3 lần nghiên cứu Luân Thị Nhung [6]. Một sự khác biệt của nghiên cứu này với nghiên cứu của Luân Thị Nhung là nghiên cứu thực hiện ở hai vị trí địa lý khác và mẫu nghiên cứu khác nhau khiến tỉ lệ các kết cuộc có sự khác nhau.

Bảng 5. Môi liên quan giữa các đặc tính mẫu nghiên cứu với kiến thức chung phòng chống sốt rét $(n=246)$

\begin{tabular}{|c|c|c|c|c|}
\hline \multirow{2}{*}{ Đặc tính mẫu } & \multicolumn{2}{|c|}{ Kiến thức phòng chống sốt rét } & \multirow{2}{*}{ Giá trị p } & \multirow{2}{*}{$\begin{array}{c}\text { PR } \\
(\text { KTC 95\%) }\end{array}$} \\
\hline & Đúng $\mathrm{n}(\%)$ & Khống đúng n (\%) & & \\
\hline $\begin{array}{c}\text { Trình độ học vấn } \\
\text { THPT trở xuống } \\
\text { Trung cấp, Cao đắng, Đại học, } \\
\text { sau Đai học }\end{array}$ & $\begin{array}{l}72(33,5) \\
19(61,3)\end{array}$ & $\begin{array}{c}143(66,5) \\
12(38,7)\end{array}$ & 0,002 & $\begin{array}{c}1,83 \\
(1,31-2,57)\end{array}$ \\
\hline $\begin{array}{c}\text { Tiên sử bản thần măc sốt rét } \\
\text { Có } \\
\text { Không }\end{array}$ & $\begin{array}{l}20(71,4) \\
71(32,6)\end{array}$ & $\begin{array}{c}8(28,6) \\
147(67,4)\end{array}$ & $<0,001$ & $\begin{array}{c}2,19 \\
(1,62-2,97)\end{array}$ \\
\hline $\begin{array}{c}\text { Tiên sử gia đình măc sốt rét } \\
\text { Có } \\
\text { Không }\end{array}$ & $\begin{array}{l}28(50,9) \\
63(32,9)\end{array}$ & $\begin{array}{l}27(49,1) \\
128(67,1)\end{array}$ & 0,015 & $\begin{array}{c}1,53 \\
(1,11-2,14)\end{array}$ \\
\hline
\end{tabular}

Trong 246 mẫu khảo sát, trình độ học vấn càng cao thì tỉ lệ có kiến thức đúng càng cao, sự khác biệt này có ý nghĩa thống kế với $\mathrm{P}=0,002$. Tiền sử bản thân có mắc sốt rét có tỉ lệ kiên thức đúng về phòng chống sốt rét cao hớn 2,19 lần người không có tiền sử bản thân mắc sốt rét, sự

khác biệt này có ý nghĩa thống kê với $\mathrm{P}<0,001$. Tî lệ người có người thân trong gia đình có tiền sử mắc sốt rét có kiến thức đúng về phòng chống sốt rét cao hơn 1,53 lần người không có người thân có tiền sử mắc sốt rét, sự khác biệt này có ý nghĩa thống kê với $\mathrm{P}=0,015$.

Bảng 6. Môi liên quan giữa kiến thức chung và thực hành trung về phòng chống sốt rét $(n=246)$

\begin{tabular}{|c|c|c|c|c|}
\hline \multirow{2}{*}{$\begin{array}{l}\text { Kiến thức } \\
\text { chung }\end{array}$} & \multicolumn{2}{|c|}{ Thực hành chung } & \multirow{2}{*}{ Giá trị P } & \multirow{2}{*}{ PR (KTC 95\%) } \\
\hline & Đúng n (\%) & Chưa đúng n (\%) & & \\
\hline $\begin{array}{c}\text { Đúng } \\
\text { Chưa đúng }\end{array}$ & $\begin{array}{c}22(24,2) \\
14(9,1) \\
\end{array}$ & $\begin{array}{c}69(75,8) \\
141(90,9) \\
\end{array}$ & 0,001 & $2,67(1,44-4,97)$ \\
\hline
\end{tabular}

Có mối liên quan có ý nghĩa thống kê giữa kiến thức chung với thực hành chung về phòng chống sốt rét. Những người có kiến thức đúng trong phòng chống sốt rét có tỉ lệ thực hành đúng cao gấp 2,67 lần so với những người chưa có kiến thức đúng, sự khác biệt này có ý nghî̉a thống kê $p=0,001$.

\section{KẾT LUẬN}

Kết quả nghiên cứu cho thấy, năng lực về phòng chống sốt rét của người dân còn tương đối thấp, kiến thức chung đúng trong phòng chống sốt rét: $37,0 \%$ và thực hành chung đúng chiếm $14,6 \%$.
Do đó, tăng cường công tác truyền thông giáo dục kiến thức về các nguyên nhân, triệu chứng, đường lây, biện pháp phòng chống và tác hại của SR trong cộng đồng. Đặc biệt những người có trình độ thấp, công việc bận rộn, thường xuyên sống trên nương rẫy, có tiền sứ 
bản thân mắc sốt rét và tiền sử gia đình mắc sốt rét cần tăng cường truyền thông giáo dục kiến thức phòng chống SR nhiều hơn nhằm nâng cao sự hiểu biết và góp phần hạn chế các tác hại do SR gây ra.

\section{TÀI LIỆU THAM KHẢO}

1. Lê Xuân Hùng và Nguyễn Mạnh Hùng (2010), "Bệnh SR và chiến lược phòng chống SR ở Việt Nam", Nhà xuất bản Y họ̣ Hà Nội,

2. Triệu Nguyên Trung (2007), "Thực trạng SR 2001-2006 và các giải pháp can thiệp ở khu vực miên Trung - Tây Nguyên", Kỷ yểu công trình NCKH 2001 - 2006, NXB y học, 12 - 25.

3. V Oluwasanmi Amusan, Yahaya Abdullahi Umar và Philip Anthony Vantsawa (2017), "Knowledge, attitudes and practices on malaria prevention and control among private security guards within Kaduna Metropolis, Kaduna StateNigeria", Sci J Public Health, 5240-5.
4. Bộ Y tế - Viện Sốt rét-KST-CT TW (2010), Đánh giá công tác PCSR năm 2009 và triển khai kế hoach PCSR năm 2011, Báo cáo nội bộ, Place Publishe.

5. Viển sốt rét - Ký sinh trùng - Cốn trùng Quy Nhơn (2019), Sốt rét tại khu vực miền Trung-Tây Nguyên năm 2019-Nguy cơ và thách thức, Báo cáo nội bộ, Place Publishe.

6. Luân Thị Nhung (2018), Kiến thức, thái độ, thực hành phòng chóng sốt rét của đồng bào S'tiêng tai huyện Bù Đăng tỉnh Bình Phước năm 2018, Luận văn tốt nghiệp, Đại học Y Dược TP. Hồ Chí Minh

7. Lê Hữu Hòa (2014), Kiến thức phòng chống sốt rét của đồng bào S'tiêng, Mnông và các yếu tố liên quan tai xã Đồng Nai và Đắk Nhau, huyện Bù Đăng-Bình Phước năm 2004, Luận văn tốt nghiệp chuyên khoa I, Đai học Y Dược TP HồChí Minh

8. Vũ Ngọc Tuấn (2017), Kiến thức, thực hành về phòng chống sốt rét của người dân xã Bù Gia Mập, huyện Bù Gia Mập, tỉnh Bình Phước năm 2017, Luận văn tốt nghiệp, Đại học Y Dược TP Hồ Chí Minh,

\section{THỰC TRANG THỰC HIỆN QUY TRÌNH LÂM SÀNG CHẨN ĐOÁN VÀ ĐIỀU TRI ĐTĐ TÝP 2 TẠI TRUNG TÂM Y TẾ HUYỆN TỨ KỲ, TỈNH HẢI DƯƠNG NĂM 2019}

\section{TÓM TẮT}

Cùng với sư gia tăng nhanh chóng của tỷ lệ hiện mắc và mới mắc của đái tháo đường (ĐTĐ) týp $\dot{2}$, việc tuân thủ theo quy trình khám chữa bệnh sẽ làm giảm thiểu tối đa những sai sót trong sàng lọc và chẩn đoán bệnh. Căn cứ vào những nội dung tại Quyết định số: 3798/QĐ-BYT ngày 27/8/2017 của Bộ Y tế về việc ban hành quy trình quy trình lâm sàng chẩn đoán và điều trị ĐTĐ týp 2, chúng tôi tiến hành nghiên cứu mô tả thực trang thực hiện quy trình lâm sàng chẩn đoán và điểu trị ĐTĐ týp 2 tai Trung tâm $Y$ tế huyện Tứ Kỳ, năm 2019. Nghiên cứu sử dụng phương pháp nghiên cứu mô tả cắt ngang, thu thập thông tin qua phỏng vấn 215 bênh nhân và rà soát hồ sơ bênh án của những bệnh nhân đó. Kết quả nghiên cứu cho thấy thông tin hành chính của người bênh được hoàn thiện tương đối đầy đủ trong hồ sơ bệnh án (HSBA) tỷ lệ trung bình có thực hiện đạt 92,8\%. Tỷ lệ có thực hiện đầy đủ các nội dung trong 7 bước của quy trình từ việc phỏng vẩn người bệnh là $79,4 \%$ và từ việc thu

\footnotetext{
${ }^{1}$ Phòng Y tế, UBND huyện Tứ Kỳ, tỉnh Hải Dương Đại học Y tế Công cộng

${ }^{3}$ Học Viện Quân Y

${ }^{4}$ Trường Đại hoc Y Dước Thái Bình

Chịu trách nhiệm chính: Khương Tùng Ân

Email: tungankhuong.kta@gmail.com

Ngày nhận bài: 9.9.2021

Ngày phản biên khoa học: 27.10.2021

Ngày duyệt bài: 10.11.2021
}

\author{
Khương Tùng Ân', Nguyễn Quỳnh Anh², \\ Lê Đình Tuân ${ }^{3}$, Ngô̂ Văn Mạnh
}

thập số liệu từ HSBA là 83,5\%. Tuy nhiên, tỷ lệ thông tin "có thực hiện" từ phỏng vấn đều cho tỷ lệ thấp hơn từ HSBA. Nghiên cứu đưa ra khuyến nghị về việc chuẩn hóa và ban hành các quy trình chuyên môn, tăng cường kiểm tra giám sát chặt chẽ theo quy định của Bộ Y tế trong đó có Quy trình lâm sàng chẩn đoán và điều trị ĐTĐ týp 2 nhằm giảm tỷ lệ không thực hiện các nội dung quy trình chuyên môn tại Trung tầm $Y$ tế huyên Tứ Kỳ̀.

Tư khoá: đái tháo đường týp 2, quy trình chẩn đoán và điều trị đái tháo đường týp 2.

\section{SUMMARY \\ CURRENT IMPLEMENTATION OF THE \\ CLINICAL DIAGNOSIS PROCESS AND \\ TREATMENT FOR PATIENTS WITH TYPE 2 \\ DIABETE AT TU KY DISTRICT HEALTH \\ CENTER, HAI DUONG PROVINCE 2019}

Along with the rapid increase in the incidence and prevalence of type 2 diabetes, adherence to medical examination and treatment procedures would minimize errors in screening and diagnos. Based on the contents of Decision No. 3798/QD-BYT dated August 27, 2017 of the Ministry of Health stipulating the implementation of clinical procedures for diagnosis and treatment of type 2 diabetes, we conducted this research. This study used descriptive research method, gathered information through interviews with 215 patients and reviewed the medical records of those patients. The research results showed that the administrative information of the patient was relatively 